\title{
Systolic anterior motion: an unusual cause of late mitral valve repair failure
}

\author{
Dibbendhu Khanra, ${ }^{1}$ Pradyot Tiwari, ${ }^{2}$ Yash Shrivastava, ${ }^{1}$ Bhanu Duggal ${ }^{1}$
}

${ }^{1}$ Cardiology, All India Institute of Medical Sciences, Rishikesh, Uttarakhand, India

${ }^{2}$ Cardiology, Apex Heart Institute, Ahmedabad, India

\section{Correspondence to}

Dr Bhanu Duggal,

bhanuduggalbmj@gmail.com

Accepted 13 July 2019
Check for updates

(C) BMJ Publishing Group Limited 2019. No commercial re-use. See rights and permissions. Published by BMJ.

To cite: Khanra D, Tiwari $P$, Shrivastava $Y$, et al. BMJ Case Rep 2019;12:e231301. doi:10.1136/bcr-2019231301

\section{DESCRIPTION}

A 50-year-old woman, who underwent mitral valve repair (MVRe) with a complete rigid mitral ring annuloplasty (Carpentier-Edwards 30; Edwards Life-sciences) 8 years ago for severe mitral regurgitation (MR) due to Barlow's disease, was apparently asymptomatic for 5 years and then started to develop progressively worsening exertional dyspnoea (New York Heart Association stage III on presentation) and intermittent palpitation for last 3 years. Details of her surgical procedures were not available as the surgeries took place 8 years back in different hospitals in different states of India. Her pulse was 78 beats per minute with a rapid upstroke. Cardiac auscultation revealed an ejection systolic murmur in the neo-aortic area which decreased on squatting. Also a pan-systolic murmur was noted in the apical region with radiation to axilla. The 12 lead surface electrocardiograms showed sinus rhythm features of left ventricular hypertrophy $(\mathrm{LVH})$ with strain pattern. Holter monitoring for 24 hours revealed paroxysmal atrial fibrillation (AF). Two-dimensional trans-thoracic echocardiography (2D-TTE) showed dilated left atrium with annuloplasty ring (figure $1 \mathrm{~A}$ ), with systolic anterior motion (SAM) of anterior mitral valve leaflet (AML) in para-sternal long axis view causing turbulence in colour Doppler (figure 1B) and M-mode (figure 1C), with concentric LVH and redundant AML touching interventricular septum in apical four-chamber view (figure 1D) causing turbulence in left ventricular outflow tract (LVOT) obstruction (figure 1E) with LVOT gradient of
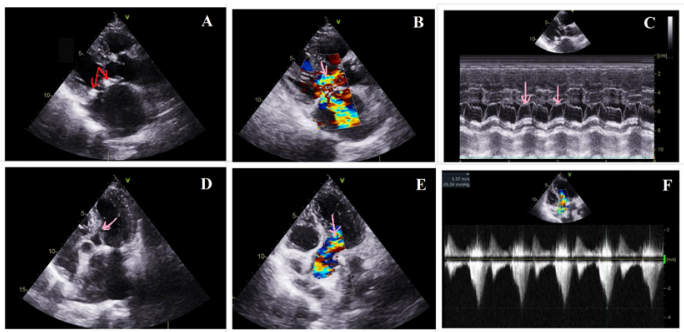

Figure 1 Two-dimensional trans-thoracic echocardiography showed dilated left atrium with annuloplasty ring (red arrows, A), with systolic anterior motion of anterior mitral leaflet (AML) in para-sternal long axis view causing turbulence in colour Doppler (pink arrow, B) and M-mode (pink arrow, C), with concentric left ventricular hypertrophy and redundant anterior mitral leaflet touching inter-ventricular septum in apical fourchamber view (pink arrow, D) causing turbulence in left ventricular outflow tract (LVOT) (pink arrow, E) with LVOT gradient of $45 \mathrm{~mm} \mathrm{Hg}(\mathrm{F})$.
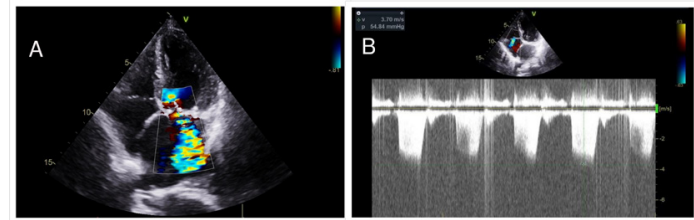

Figure 2 Two-dimensional trans-thoracic echocardiography of a post-mitral valve repair. (A-B) Patient showing severe mitral regurgitation with posterior jet in apical four-chamber view (A) and mild tricuspid regurgitation with peak right ventricular systolic pressure gradient of $54 \mathrm{~mm} \mathrm{Hg}$ were also noted in continuous wave Doppler (B).

$45 \mathrm{~mm} \mathrm{Hg}$ (figure 1F). Severe MR with posterior jet (figure 2A) and mild tricuspid regurgitation (TR) with peak right ventricular systolic pressure gradient of $54 \mathrm{~mm} \mathrm{Hg}$ were also noted (figure $2 \mathrm{~B}$ ).

Following the MVRe, the patient was apparently well on medical treatment with beta-blocker, diuretic and anticoagulant. For last 3 years, she developed progressively worsening exertional dyspnoea despite medical treatments. And her echocardiography revealed SAM causing LVOT obstruction. Dose of beta-blockers were optimised and yet the patient remained symptomatic with dyspnoea and SAM in echocardiography was persistent. Opinion was taken from the cardiothoracic surgeons and the patient was posted for re-operation after informed consent for MVRe or mitral valve replacement (MVR). Midline re-sternotomy was done, cardiopulmonary bypass was established and mitral valve was approached through the left atrium. AML was found to be thick and redundant and entire AML was excised. No thickened papillary muscle was seen to cause LVOT obstruction. The LVOT gradient came down to $5 \mathrm{~mm} \mathrm{Hg}$ but intraoperative trans-oesophageal echocardiography (TOE) revealed no reduction of MR. So, decision of MVR was made on the table. Annuloplasty ring was excised, and MVR with bileaflet metallic valve $(30 \mathrm{~mm}$, St Jude Medical) was done successfully with favourable postoperative evolution. The patient was discharged 14 days after surgery. The patient is on warfarin, aspirin and beta-blocker. Three months later, the patient is asymptomatic and free from SAM and no MR on repeated TTE.

SAM is a known but infrequent complication of mitral reconstructive surgery which may result from patient-related factors like excessive leaflet tissue (Barlow's disease) with a tall posterior leaflet $(>15 \mathrm{~mm})$, ratio between the heights of the anterior and posterior leaflets $\leq 1.3$, aorto-mitral plane angle $<120^{\circ}$, short distance between the 
inter-ventricular septum and the mitral leaflet co-aptation point $(<15 \mathrm{~mm})$, small and hyperkinetic left ventricle and anterior displacement of the papillary muscles and procedure-related factors like inadequate reduction of the posterior leaflet height (which still remains $>15 \mathrm{~mm}$ ) and insertion of a small prosthetic ring. ${ }^{1-3}$ Surgical techniques of MVRe have been tailored to prevent SAM which include leaflet resection with sliding plasty, folding plasty, the posterior leaflet shortening technique, partial ring rather than complete ring, septal myomectomy in case of bulging sub-aortic inter-ventricular septum and edge-to-edge (EE) suture. ${ }^{3-6}$ However, if SAM is detected during weaning from cardiopulmonary bypass, measures can be undertaken to minimise SAM by discontinuing ionotrops followed by volume expansion, use of intravenous beta-blockers and partial digital compression of the ascending aorta to increase afterload. ${ }^{67}$ Late clinical outcome of patients who had transient SAM was found to be satisfactory with conservative measures. ${ }^{6}$ However, if SAM persists and the patient deteriorates haemodynamically, surgical revisions may be required which include EE suture, posterior leaflet shortening, excision of anterior leaflet and rarely MVR. ${ }^{248}$

SAM is an unusual cause of MV repair failure after 8 years of surgery and has rarely been reported in the literature. ${ }^{9}$ This may occur due to multitudes of reasons including inadequate excision of redundant AML, regrowth of AML postoperatively, missing diagnosis of thickened papillary muscle which later causes SAM, mitral ring implantation without leaflet excision. A large surface of leaflet co-aptation should be ensured to achieve

\section{Learning points}

- The degree of systolic anterior motion (SAM) after mitral valve repair can range from minor chordal protrusion with minimal left ventricular outflow tract obstruction and trivial mitral regurgitation (MR) to more severe obstruction with massive MR.

- SAM can be transient and reversible or resistant, not responding to conservative approach and requiring surgical revision.

- SAM typically occurs immediately after the reparative surgery and it is detected while weaning from cardiopulmonary bypass. Occasionally it is discovered after surgery, and exceptionally it is observed postoperatively after years. good long-term results in MVRe. However, too much reduction of the height of the AML may compromise the long-term durability of the repair. ${ }^{10}$

Details of previous surgery were not available in our case. During the re-operation, AML was found to be thick and redundant and may be due to incomplete excision of AML or regrowth of AML due to degenerative Barlow's disease. Considering the symptoms of the patient and the lacunae of evidence in managing SAM so late after MVRe, and the persistence of MR despite excision of redundant AML tissue, the surgeons advised for MVR in our case.

Contributors BD, YS: conception and discussion; DK, PT: case report and investigations; DK, BD: critical appraisal.

Funding The authors have not declared a specific grant for this research from any funding agency in the public, commercial or not-for-profit sectors.

Competing interests None declared.

Patient consent for publication Obtained.

Provenance and peer review Not commissioned; externally peer reviewed.

\section{REFERENCES}

1 Maslow AD, Regan MM, Haering JM, et al. Echocardiographic predictors of left ventricular outflow tract obstruction and systolic anterior motion of the mitral valve after mitral valve reconstruction for myxomatous valve disease. J Am Coll Cardiol 1999;34:2096-104.

2 Varghese R, Itagaki S, Anyanwu AC, et al. Predicting systolic anterior motion after mitral valve reconstruction: using intraoperative transoesophageal echocardiography to identify those at greatest risk. Eur J Cardiothorac Surg 2014;45:132-8.

3 Loulmet DF, Yaffee DW, Ursomanno PA, et al. Systolic anterior motion of the mitral valve: a 30-year perspective. J Thorac Cardiovasc Surg 2014;148:2787-94.

4 Said SM, Schaff HV, Suri RM, et al. Bulging subaortic septum: an important risk factor for systolic anterior motion after mitral valve repair. Ann Thorac Surg 2011;91:1427-32.

5 Myers PO, Khalpey Z, Maloney AM, et al. Edge-to-edge repair for prevention and treatment of mitral valve systolic anterior motion. J Thorac Cardiovasc Surg 2013:146:836-40.

6 Kuperstein R, Spiegelstein D, Rotem G, et al. Late clinical outcome of transient intraoperative systolic anterior motion post mitral valve repair. J Thorac Cardiovasc Surg 2015;149:471-6.

7 Alfieri O, Lapenna E. Systolic anterior motion after mitral valve repair: where do we stand in 2015? Eur J Cardiothorac Surg 2015;48:344-6.

8 De Bonis M, Lapenna E, Buzzatti N, et al. Can the edge-to-edge technique provide durable results when used to rescue patients with suboptimal conventional mitral repair? Eur J Cardiothorac Surg 2013;43:e173-9.

9 Zegdi R, Carpentier A, Doguet F, et al. Systolic anterior motion after mitral valve repair: an exceptional cause of late failure. J Thorac Cardiovasc Surg 2005;130:1453-4.

10 Quigley RL, Garcia FC, Badawi RA. Prevention of systolic anterior motion after mitral valve repair with an anterior leaflet valvuloplasty. J Heart Valve Dis 2004;13:927-30.

Copyright 2019 BMJ Publishing Group. All rights reserved. For permission to reuse any of this content visit

https://www.bmj.com/company/products-services/rights-and-licensing/permissions/

BMJ Case Report Fellows may re-use this article for personal use and teaching without any further permission.

Become a Fellow of BMJ Case Reports today and you can:

- Submit as many cases as you like

- Enjoy fast sympathetic peer review and rapid publication of accepted articles

- Access all the published articles

- Re-use any of the published material for personal use and teaching without further permission

Customer Service

If you have any further queries about your subscription, please contact our customer services team on +44 (0) 2071111105 or via email at support@bmj.com.

Visit casereports.bmj.com for more articles like this and to become a Fellow 